\title{
Embryonal Tumor with Multilayered Rosettes in a 3-Year-Old Girl: Case Report
}

\author{
Aparna GOVINDAN ${ }^{1}$, Muralikrishnan VP², Jacob Paul ALAPATT ${ }^{2}$ \\ ${ }^{1}$ Government Medical College, Department of Pathology, Kozhikode, India \\ ${ }^{2}$ Government Medical College, Department of Neurosurgery, Kozhikode, India
}

Corresponding author: Aparna GOVINDAN aparnabyju@gmail.com

\section{ABSTRACT}

Embryonal tumor with multilayered rosettes (ETMR) is a new entity in the group of primitive neuroectodermal tumors of the central nervous system (CNS). It combines histopathological features of neuroblastoma and ependymoblastoma. This tumor occurs mostly in the first five years of life. A hallmark cytogenetic abnormality at the chromosome locus 19q13.42 has been identified. The authors report a case of ETMR in the parietooccipital region in a 3-year-old girl who presented with features of raised intracranial tension. The exact diagnosis could be made by the finding of true rosettes in a single low power field. ETMR is a newly described rare pediatric CNS tumor and large case studies regarding its differentiation from usual PNETs are lacking. Reporting each case with the morphological features of this tumor would add to the existing data on these tumors as regards pathology, diagnosis and management.

KEYWORDS: Abundant neuropil, Embryonal tumor, Ependymoblastoma, Multilayered rosettes, Synaptophysin, True rosettes

\section{INTRODUCTION}

$\mathrm{E}$ mbryonal tumor with multilayered rosettes (ETMR) is a new entity among the embryonal tumors of the central nervous system (CNS), included as a separate entity in the World Health Organization (WHO) classification of CNS tumors, 2016. The tumors which were previously referred to as embryonal tumor with abundant neuropil and true rosettes (ETANTR), ependymoblastoma and medulloepithelioma are now included under this heading (5). Large case series of ETMR are very few and description of each case would add to the existing knowledge on the natural history and prognostic indicators of this rare tumor. So, we report a case of ETMR in a 3-year-old girl who succumbed to the illness in the immediate postoperative period.

\section{CASE REPORT}

A 3-year-old girl was referred to the neurosurgical services with features of increased intracranial pressure. There was history of increased tiredness in the child and vomiting for three months. The parents consulted a pediatrician who detected left hemiparesis. On examination, the child was drowsy, but obeying commands. There was bilateral established papilledema, left upper motor neuron facial palsy and hemiparesis. The Glasgow coma scale was E3M6V2. The child had aspiration pneumonia on admission. Cranial magnetic resonance imaging (MRI) revealed a large right-sided parieto-occipital lesion extending to ventricles with superior sagittal sinus compression (Figure 1A). Areas of contrast enhancement were seen towards the side with dural attachment (Figure 1B). There were multiple foci of calcification within the tumor. Right parieto-occipital craniotomy and gross total excision of tumor was done. Bone was thin and the dura was tense. The soft, grayish- white tumor with necrotic areas had breached the dura near the midline. There was no plane between the superior sagittal sinus and the tumor in the posterior third. There were firm areas in between and areas of calcification. Medially, there was a cystic part close to the wall of the lateral ventricle. The child had drop in oxygen saturation on the night of surgery which could not be corrected. The cause of death may be respiratory failure unrelated to surgery. 

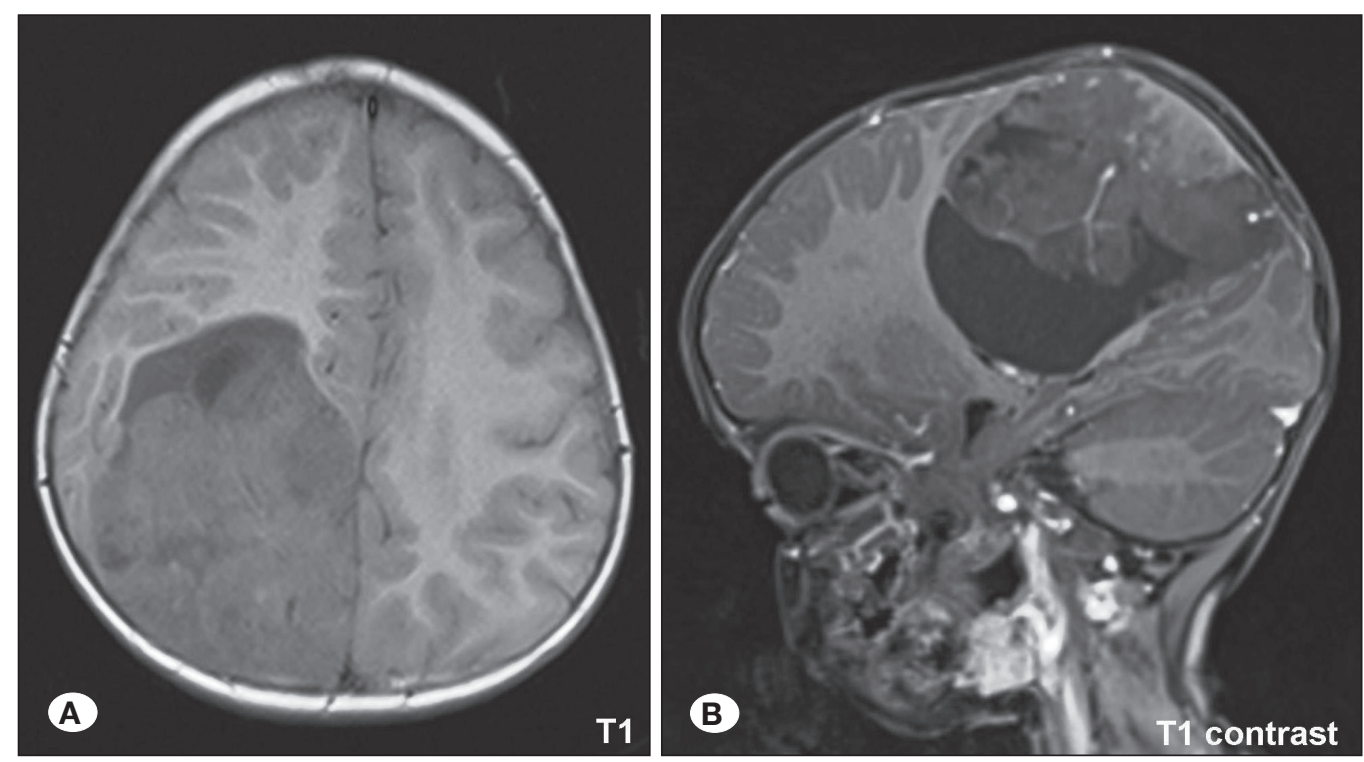

Figure 1: A) T1 weighted axial MRI showing a large tumor in the right parietooccipital region attached to dura causing superior sagittal sinus compression and midline shift. B) Post-contrast T1 weighted sagittal MRI showing mild contrast enhancement in the regions near the dural attachment.

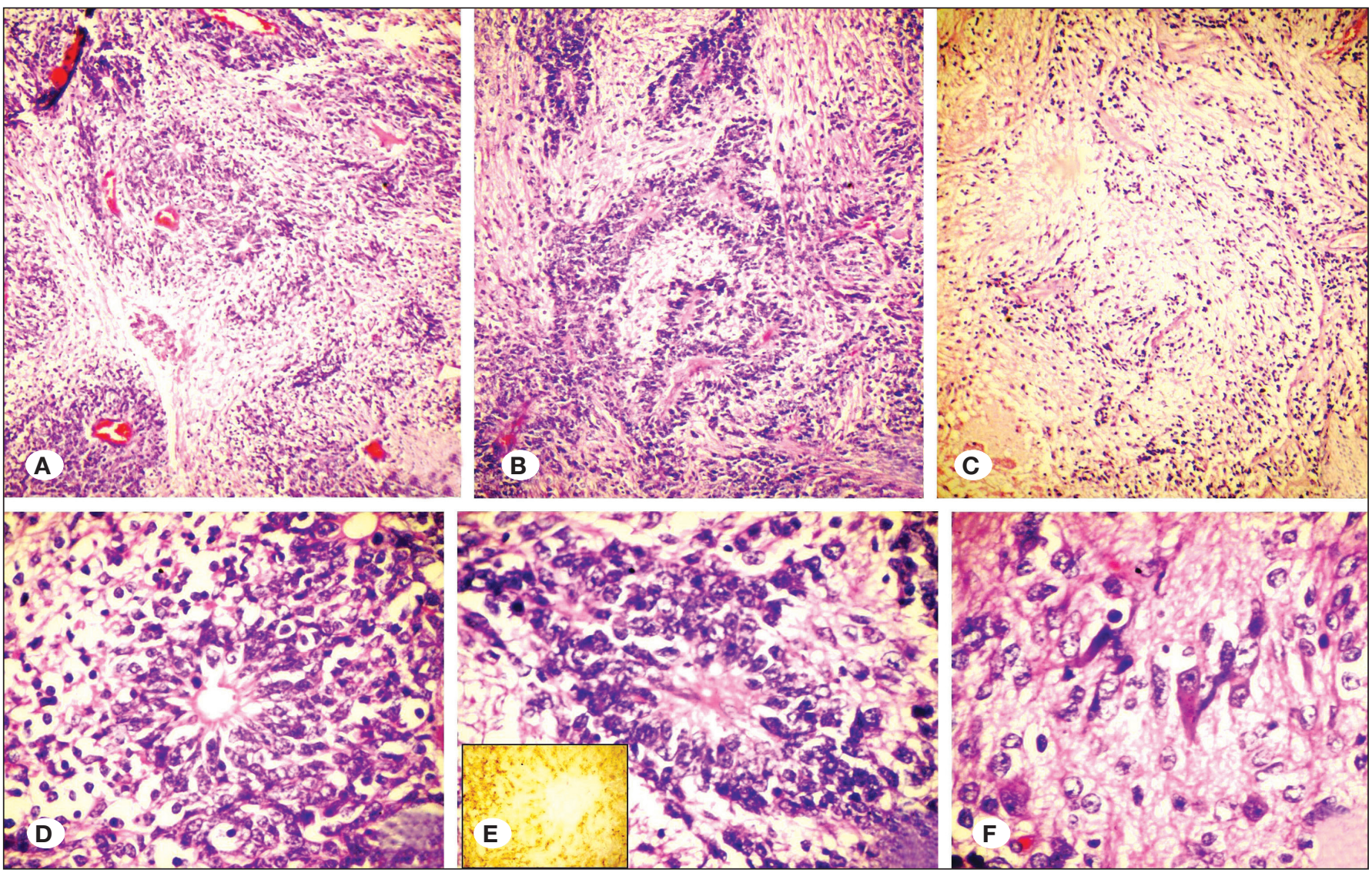

Figure 2: A) Highly cellular areas composed of small undifferentiated cells with ependymoblastic true rosettes intermingled with paucicellular areas. A focus of necrosis is seen (Hematoxylin \& Eosin, x100). B) Cells arranged in perivascular pseudorosette pattern (Hematoxylin \& Eosin, x100). C) Paucicellular areas with abundant neuropil (Hematoxylin \& Eosin, x100). D) High power view of multilayered ependymoblastic rosettes (Hematoxylin \& Eosin, x400). E) High power view of perivascular pseudorosette (Hematoxylin \& Eosin, x400) (inset- synaptophysin positivity in neuropil, x400). F) Ganglion cells in paucicellular areas (Hematoxylin \& Eosin, x400). 
Histopathological examination showed a tumor with areas of high cellularity intermingled with paucicellular areas exhibiting abundant neuropil (Figure 2A, C). The tumor was punctuated by necrotic foci. In the cellular areas, the cells were mostly small and undifferentiated and arranged in sheets and perivascular pseudorosette pattern (Figure 2B, D). Focally there were cells with moderate clear cytoplasm. Mitotic activity was brisk. In the neuropil areas larger cells with vesicular nuclei and indistinct cytoplasmic borders were seen. In a single low power focus we could appreciate multilayered ependymoblastic rosettes merging into the neuropil areas (Figure 2E). Scattered ganglion cells were noted within the neuropil areas (Figure 2F). Immunohistochemistry showed the cells to be positive for vimentin. The neuropil was positive for synaptophysin (Figure 2E, inset). A diagnosis of embryonal tumor with multilayered rosettes was made.

\section{DISCUSSION}

Embryonal tumor with multilayered rosettes is a distinct name in the family of embryonal tumors of the CNS and includes tumors with features of ETANTR, ependymoblastoma and medulloepithelioma. The finding of a focal amplification of an oncogene and overlap in the clinical features made researchers group these tumors into a single entity. It was first described by Eberhart et al. in the year 2000 as a pediatric neuroblastic tumor with abundant neuropil and ependymoblastic rosettes (3). Around 80 cases of the entity have been described with the largest case series being that of seven cases included in a review of 29 cases of ETANTR by Gessi et al. in 2009 $(1,4,9)$. This is a rare tumor which occurs mostly in the cerebral cortex of children below the age of four years and has a poor prognosis $(1,7)$. A female preponderance is described. On imaging, the tumors are usually large solid masses with or without a cystic component and patchy or no contrast enhancement in spite of the higher grade $(1,4)$. In the present case also the tumor was in a girl child and was large with contrast enhancement. Many cases are reported to have dural attachment as the present one (1).

Histopathologically the hallmark of ETMR is the presence of ependymoblastic rosettes and undifferentiated small cells with or without neoplastic neuropil. There is as yet no criterion on the proportion of tumor tissue with rosettes that is necessary to make a diagnosis of ETMR and it would be worthwhile to study the relevance of this proportion on the course of the disease. In the present case but for the single focus of ependymoblastic rosettes the tumor would have been labeled simply as a CNS embryonal tumor. The unresponsiveness of ETMR to current treatment protocols makes it necessary to differentiate it from other embryonal tumors $(7,8)$. Immunohistochemically the tumor cells are positive for vimentin and the neuropil is positive for synaptophysin. MIB-1 labeling index will be very high as for all embryonal tumors.

The breakthrough discovery of a hallmark cytogenetic abnormality ie, focal amplification of miRNA cluster at chromosome locus 19 q13.42 was made in these tumors by Korshunov et al. and Pfister et al. $(6,11)$. As there was considerable debate regarding the existence of a separate entity as 'ependymoblastoma', it was prudent to put ETANTR and ependymoblastoma into a single entity with the discovery of this amplification (10). C19MC amplification or fusion defines the tumor now. LIN28A was identified as a specific marker by gene expression profiling and antibodies were developed for immunohistochemical diagnosis of the tumor $(2,7)$. With widespread availability of this marker, more cases will be diagnosed. We could not do immunohistochemistry or gene amplification studies as the facilities are not available at our centre.

\section{CONCLUSION}

The differences in survival and prognostic factors between ETMR and other CNS embryonal tumors and the need to differentiate them in terms of treatment and prognostication have not as yet been clearly defined. Large series of cases have to be studied to precisely determine these variables. Therefore reporting each case with the morphological features of this tumor would add to the existing data on these tumors as regards pathology, diagnosis and management.

\section{- REFERENCES}

1. Adamek D, Sofowora KD, Cwiklinska M, Herman-Sucharska I, Kwiatkowski S: Embryonal tumor with abundant neuropil and true rosettes: An autopsy case-based update and review of the literature. Childs Nerv Syst 29:849-854, 2013

2. Ceccom J, Bourdeaut F, Loukh N, Rigau V, Milin S, Takin R, Richer W, Uro-Coste E, Couturier J, Bertozzi Al, Delattre O, Delisle MB: Embryonal tumor with multilayered rosettes: Diagnostic tools update and review of the literature. Clin Neuropathol 33(1):15-22, 2014

3. Eberhart CG, Brat DJ, Cohen KJ, Burger PC: Pediatric neuroblastic brain tumors containing abundant neuropil and true rosettes. Pediatric Dev Pathol 3:346-352, 2000

4. Gessi M, Giangaspero F, Lauriola L, Gardiman M, Scheithauer BW, Halliday W, Hawkins C, Rosenblum MK, Burger PC, Eberhart CG: Embryonal tumors with abundant neuropil and true rosettes: A distinctive CNS primitive neuroectodermal tumor. Am J Surg Pathol 33(2):211-217, 2009

5. Korshunov A, McLendon R, Judkins AR, Pfister S, Eberhart CG, Fuller GN, Sarkar C, Ng HK, Huang A, Kool M, Wesseling $\mathrm{P}$ : Embryonal tumour with multilayered rosettes, C19MCaltered. In: Louis DN, Ohgaki H, Wiestler OD, Cavenee WK (eds), WHO Classification of Tumours of the Central Nervous System. Lyon: IARC, 2016: 201-205

6. Korshunov A, Remke M, Gessi M, Ryzhova M, Hielscher T, Witt H, Tobias V, Buccoliero AM, Sardi I, Gardiman MP, Bonnin J, Scheithauer B, Kulozik AE, Witt O,Mork S, von Deimling A, Wiestler OD, Giangaspero F, Rosenblum M, Pietsch T, Lichter P, Pfister SM: Focal genomic amplification at 19q13.42 comprises a powerful diagnostic marker for embryonal tumors with ependymoblastic rosettes. Acta Neuropathol 120:253260, 2010 
7. Korshunov A, Ryzhova M, Jones DTW, Northcott PA, van Sluis P, Volckmann R, Koster J, Versteeg R, Cowdrey C, Perry A, Picard D, Rosenblum M, Giangaspero F, Aronica E, Schüller U, Hasselblatt M, Collins V P, von Deimling A, Lichter P, Huang A, Pfister S M, Kool M: LIN28A immunoreactivity is a potent diagnostic marker of embryonal tumor with multilayered rosettes (ETMR). Acta Neuropathol 124:875-881, 2012

8. Manjila S, Ray A, Hu Y, Cai DX, Cohen ML, Cohen AR: Embryonal tumors with abundant neuropil and true rosettes: 2 illustrative cases and a review of the literature. Neurosurg Focus 30(1):E2, 2011
9. Neelima R, Easwer HV, Kapilamoorthy TR, Hingwala DR, Radhakrishnan VV: Embryonal tumor with multilayered rosettes: Two case reports with a review of the literature. Neurol India 60(1):96-99, 2012

10. Paulus W, Kleihues P: Genetic profiling of CNS tumors extends histological classification. Acta Neuropathol 120:269270, 2010

11. Pfister SM, Remke M, Castoldi M, Bai AH, Muckenthaler MU, Kulozik A, von Deimling A, Pscherer A, Lichter P, Korshunov A: Novel genomic amplification targeting the microRNA cluster at $19 q 13.42$ in a pediatric embryonal tumor with abundant neuropil and true rosettes. Acta Neuropathol 117:457-464, 2009 